\title{
PROTECTING WILD ANIMALS FROM UNNECESSARY
}

\section{SUFFERING $^{*}$}

\begin{abstract}
$\underline{\text { Abstract }}$
This article compares the protection from unnecessary suffering afforded to wild animals with that afforded to domesticated animals and animals under human control. It considers various speciesspecific bio-diversity- and conservation-based protection for wild animals, under legislation such as the Wildlife and Countryside Act 1981 and the Conservation of Habitats and Species Regulations 2010, as well as the general protection from intentionally inflicted unnecessary suffering afforded to wild mammals under the Wild Mammals (Protection) Act 1996. The article then compares the standard of protection afforded to wild animals with that afforded to non-wild animals under section 4 of the Animal Welfare Act 2006, which criminalises unnecessary suffering unreasonably caused to non-wild animals.
\end{abstract}

Keywords: Wild animals - Unnecessary suffering - Unreasonableness - Criminal Law Negligence

\section{Introduction}

Under the Wildlife and Countryside Act 1981, it is, subject to various defences and derogations, a criminal offence, inter alia, intentionally (or, in some cases, recklessly) ${ }^{1}$ to kill, injure or take

\footnotetext{
${ }^{*}$ Gareth Spark, UEA Law School, gareth.spark@uea.ac.uk. Thanks are due to my colleagues Deborah Ives and Dr. Rob Heywood, to the editor of this journal and to the anonymous reviewers for their helpful comments on earlier drafts. Any errors or omissions remain my own.
} 
Protecting Wild Animals from Unnecessary Suffering

certain wild animals; to disturb their shelter; to use certain methods of killing or taking them even if the killing or taking is itself lawful; or to offer them for sale, dead or alive. Similar protections exist for certain wild animals of species designated 'European protected species' under the Conservation of Habitats and Species Regulations 2010. Likewise, it is an offence to take or intentionally kill any deer at night, ${ }^{2}$ and certain types of deer are protected from being taken or intentionally killed during the closed season. ${ }^{3}$ Furthermore, it is an offence to use various methods to take or kill a deer; ${ }^{4}$ or wilfully to kill, injure or take a badger, or to attempt to do so, or intentionally or recklessly to disturb a badger sett, unless lawfully permitted; or cruelly to ill-treat a badger. ${ }^{5}$ In short, various actions committed in relation to an extensive array of wild animals amount to an offence, and the prohibited actions are ones which often would cause suffering to any animal which was subject to them.

As such, it can be seen that there are, in one sense, wide legal protections for many wild animals in England and Wales. There is, however, no general protection from unnecessary suffering applicable to wild animals. Section 4(1) of the Animal Welfare Act 2006 (AWA) criminalises acts or omissions which cause unnecessary suffering to an animal, if the act/omission is engaged in by a person who knew or ought reasonably to have known that his/her conduct would cause, or would be likely to cause, an animal to suffer. However, the offence applies only to 'protected animals', defined in section 2 AWA as animals which are '(a)...of a kind...commonly domesticated in the British Islands, (b)...under the [permanent or temporary] control of man..., or (c)...not living in a wild state.' Therefore, section 4(1) clearly does not apply to truly wild animals: i.e., to animals of a

\footnotetext{
${ }^{1}$ eg s 9 Wildlife and Countryside Act 1981.

2 s 3 Deer Act 1991.

3 ibid s 2 .

${ }^{4}$ ibid s 4 .

${ }^{5}$ ss 1-3 Protection of Badgers Act 1992.
} 
Protecting Wild Animals from Unnecessary Suffering

kind not commonly domesticated in Britain and truly living in a wild state, not under the permanent or temporary control of man.

The closest thing to a general prohibition against causing unnecessary suffering to wild animals in England and Wales is section 1 of the Wild Mammals (Protection) Act 1996 (WMPA), by which a person commits an offence if s/he 'mutilates, kicks, beats, nails or otherwise impales, stabs, burns, stones, crushes, drowns, drags or asphyxiates any wild mammal with intent to inflict unnecessary suffering'. In one limited sense, this offence is wider than section 4(1) AWA, because it does not require proof of unnecessary suffering, whereas the latter does. However, it is unlikely that a person will perform one of the prohibited actions (mutilating, kicking, beating, etc., a wild mammal) with intent to inflict unnecessary suffering but without actually causing unnecessary suffering. Furthermore, the WMPA offence applies only to mammals, and the mens rea element is narrower than that in section 4(1) AWA, requiring proof of intent to inflict unnecessary suffering, rather than the offence being committed on the basis of unreasonable ${ }^{6}$ actions which a person knows or ought reasonably to know will (or will likely) cause an animal to suffer. As such, it is contended that this offence can properly be said to be narrower than the section 4(1) AWA offence. The purpose of this article is to consider (i) why wild animals are afforded less protection from unnecessary suffering than non-wild animals and (ii) whether this lesser standard is appropriate.

\footnotetext{
${ }^{6}$ s 4(1) AWA requires conduct which caused an animal to suffer unnecessarily, when the defendant at least ought reasonably to have known that an animal was likely to suffer, and s 4(3) states that whether 'suffering could reasonably have been avoided or reduced' is relevant to determining whether it is unnecessary. It is contended that these elements ensure that the defendant's conduct will have been unreasonable. This will be addressed further below.
} 
Protecting Wild Animals from Unnecessary Suffering

2 Why Are Wild Animals Afforded Less Protection from Unnecessary Suffering than Non-wild

$\underline{\text { Animals? }}$

As the Law Commission noted, historically, '[w]ildlife was treated by the law as an economic or leisure resource, or as something to be controlled, rather than as something worthy of protection in its own right. ${ }^{97}$ Indeed, the biblical notion that non-human animals existed for the use of humans pervaded attitudes towards all animals, wild and non-wild, well into the 1800s. Even Lord Erskine, an early proponent of animal protection legislation, did not seek to deny man's 'dominion' over non-human animals, instead arguing that the law should protect animals under human control because such 'dominion [was] a moral trust'. ${ }^{8}$ Moreover, as Parliament began to enact laws to protect animals, many proponents of such measures supported them, not for the sake of the animals themselves, but for the sake of human society. For example, when, in the early 1800s, Bills seeking to prohibit bull-baiting were introduced into Parliament, supporters of the Bills based their main arguments in favour of the measures on the need to maintain public order and improve human morals. ${ }^{9}$ Even as society's awareness and attitudes began to develop and people began to recognise the sentience of animals, animal protection legislation continued to be supported primarily on the basis of improving human society, by preventing the public disorder which arose at many animalfighting and -baiting events and by arguing that inflicting, and even witnessing, cruelty to animals induced in people a callousness which adversely affected their attitudes and behaviour towards other people. ${ }^{10}$

\footnotetext{
${ }^{7}$ Law Commission, Wildlife Law (Law Com CP No 206, 2012) [1.3].

${ }^{8}$ HL Deb $15^{\text {th }}$ May 1809, vol 14, cols 554.

${ }^{9}$ Mike Radford, Animal Welfare Law in Britain: Regulation and Responsibility (OUP 2001) 33-35.

10 eg, Richard Martin MP, HC Deb, $24^{\text {th }}$ February 1825, vol 12, col 657, William Smith MP, HC Deb, $11^{\text {th }}$ March 1825 , vol 12, col 1009-1010) and Sir Francis Burdett, MP, HC Deb, $11^{\text {th }}$ March 1825, vol 12, col 1013). See also Re Wedgwood [1915] 1 Ch 113 (public benefit requirement of charitable trusts satisfied by testamentary gift for the 'protection and benefit' of animals on the basis that it would tend to promote public morality).
} 
Protecting Wild Animals from Unnecessary Suffering

The use of wild animals was not generally affected by such arguments. When animals remained in a truly wild state, human interaction with them primarily involved hunting and shooting, activities which were generally undertaken by affluent members of society and which did not attract the unruly behaviour associated with animal-fighting and -baiting. Moreover, whilst many recognised that hunting and shooting could be argued to be as cruel as animal-fighting and baiting, ${ }^{11}$ there existed a desire not to interfere with the former activities, which were widely practised by the upper classes. ${ }^{12}$ As such, the original animal protection legislation did not apply to truly wild animals.

As Radford notes, ${ }^{13}$ when legislation was enacted to protect truly wild animals, it was passed, not to protect wild animals from unnecessary suffering, but to conserve species. For example, the first legislation in this area was the Sea Birds Preservation Act 1869, which provided for a closed season in which certain seabirds could not be shot and a restriction on egg-collecting. The protection offered by the first legislation was gradually extended to protect all wild birds to some degree. Yet the protection of wild 'mammals [was] ignored' because there were no concerns about the population levels of such species, ${ }^{14}$ and ' $[\mathrm{t}]$ he emphasis in wildlife conservation has been on the protection of endangered species rather than individual animals'. ${ }^{15}$ Therefore, laws protecting wild animals were 'primarily concerned to preserve species populations, not [to regulate] the treatment of individual animals', ${ }^{16}$ and species-conservation 'is very different from the protection of individual animals' ${ }^{17}$

\footnotetext{
${ }^{11}$ eg William Windham MP, HC Deb, $13^{\text {th }}$ June 1809, vol 14, col 1040.

${ }^{12}$ Radford (n 9).

13 ibid 77-79.

14 ibid 78. Radford notes that the exception to this was the hare, 'whose population had dramatically declined because of the numbers being taken for food.'

${ }^{15}$ Robert Garner, Political Animals (MacMillan 1998) 28.

${ }^{16}$ Radford (n 9) 79.

${ }^{17}$ Garner (n 15) 41.
} 
Protecting Wild Animals from Unnecessary Suffering

The trend of protecting wild animals on conservation grounds, rather than protecting them from unnecessary suffering per se, was not changed with adoption of the Protection of Animals Act 1911, which excluded truly wild animals from its scope. ${ }^{18}$ Indeed, the trend largely continued with the Wildlife and Countryside Act 1981. Although the Act prohibits a range of actions which can cause unnecessary suffering to wild animals (for example, taking them, injuring them, and killing or taking them by certain methods), the fact that the activities it prohibits are ones which can have a negative effect on wild populations and bio-diversity, and are prohibited regardless of whether they cause an animal to suffer, demonstrates that the Act is primarily concerned with speciesconservation. Indeed, the Act is an example of the point Harrop makes when he states that, '[o]ften [wild animal welfare] law derives...incidentally or even accidentally from measures designed to conserve species'. ${ }^{19}$ Yet Harrop also argues that 'conservation motives can never be enough' to protect wild animals from unnecessary suffering. ${ }^{20}$

Section 1 WMPA was the first general legislation to seek to regulate the treatment of individual wild animals. As such, 'the law [now] protects individual [wild] animals from harm above a permitted level', balancing this protection with human interests, such as the right to 'exploit...wildlife as a valuable natural asset." ${ }^{21}$ The WMPA seeks to reflect this balance through the section 1 offence, which sets the acceptable level of harm to wild mammals, and the section 2 exemptions, which protect, inter alia, the right to exploit wild mammals for human purposes. The

\footnotetext{
${ }^{18}$ Joan Schaffner An Introduction to Animals and the Law (MacMillan 2011) 60, notes that the same is generally true in the United States.

${ }^{19}$ Stuart Harrop, ‘The Dynamics of Wild Animal Welfare Law' (1997) 9 JEL 287, 287.

${ }^{20} \mathrm{ibid}, 298$. Indeed, Harrop notes that conservation imperatives and the desire to protect wild animals from suffering might conflict. eg Stuart Harrop, 'Wild Animal Welfare in International Law: The Present Position and the Scope for Development' (2013) 4 Global Policy 381, 382. See also Garner (n 15) 41-42.

${ }^{21}$ Law Commission (n 7) [1.10].
} 
Protecting Wild Animals from Unnecessary Suffering

primary question for present purposes is whether the requirement of intent to inflict unnecessary suffering sets the appropriate level of protection and properly balances this with human interests. ${ }^{22}$ As originally introduced, the Wild Mammals (Protection) Bill did not include an express mens rea element, ${ }^{23}$ the main offence being committed (subject to exemptions) whenever 'any person cruelly kicks, beats or tortures any wild mammal'. ${ }^{24}$ The adverb 'cruelly' could have been interpreted to impose some sort of mens rea element, but Lord Renton suggested that the offence would have been one of strict liability, applying '[e]ven if a person kicks, beats, [etc.,] a wild mammal accidentally or without intending to do it, or without intending to be cruel' ${ }^{25}$ His Lordship suggested that it was necessary to add to the offence "the word "knowingly", or "intentionally", or "wilfully", ${ }^{26}$ Therefore, the primary reason for adding a mens rea element was to seek to balance the need to protect wild mammals with the need not to impose too strict a liability on people. However, no apparent consideration was given in Parliamentary debate to whether criminalising, say, unreasonable or reckless actions which caused a wild mammal to suffer unnecessarily would strike the appropriate balance. When discussing exemptions which applied under the draft Bill at the time, Baroness Mallalieu raised concerns about the defence relating to mercy killing of a wild mammal which has no reasonable chance of recovering, suggesting that it would be inappropriate to

\footnotetext{
${ }^{22}$ For general discussion of how to balance wild animal protection and human interests, see Sarah Bertouille, 'Wildlife Law and Policy' (2012) 35 Animal Biodiversity and Conservation 159, and Harrop, 'Wild Animal Welfare in International Law' (n 20).

${ }^{23}$ On $4^{\text {th }}$ December 1991, a Bill of the same was introduced, and that Bill required that the defendant wilfully inflicted unnecessary suffering on, or cruelly ill-treated, a wild mammal. See, HC Deb, 14 February 1992, vol 203, col 1217. However, this Bill was defeated at its second reading (col 1286).

${ }^{24}$ House of Commons Research Paper, Wild Mammals (Protection) Bill [Bill 16 1995/96] (HC Research Paper 96/13 1996) <http://www.parliament.uk/business/publications/research/briefing-papers/RP96-13/wild-mammals-protectionbill-199596> accessed 4th August 2014.

${ }^{25}$ HL Deb, 19 October 1995, vol 566, col 864.

${ }^{26}$ ibid col 865 .
} 
Protecting Wild Animals from Unnecessary Suffering

convict a person who honestly, but unreasonably, believed that the animal had no chance of recovering. ${ }^{27}$ Nonetheless, this provision was included in s 2 WMPA. As it was not thought that reasonableness was an unmanageable principle when setting the scope of an exemption from the section 1 offence, there seems to be no reason to suggest that it would have been an inappropriate concept to define the offence. More importantly, even if it was believed to be inappropriate, the lack of explicit consideration of the concept as the mens rea element of the offence meant that no justification was offered for such a belief if it was held.

The crucial point is that there was no detailed consideration of why wild mammals should not have been afforded protection from unreasonably caused unnecessary suffering, as non-wild animals were under s 1 Protection of Animals Act 1911 at the time (and as they now are under s 4(1) AWA). One can certainly speculate that the desire to avoid being seen as a potential means of challenging the legality of hunting was relevant to adoption of the standard of intentionality, as opposed to unreasonableness or recklessness. ${ }^{28}$ It is not hard to envisage prosecutions having been brought alleging that those engaged in hunting unreasonably or recklessly caused unnecessary suffering to wild mammals, if either of these standards had been adopted as the mens rea element of the offence. Indeed, the reports and debates concerning the Bill contain repeated references to amendments having been made to ensure that it was not blocked by supporters of hunting. ${ }^{29}$

\footnotetext{
27 ibid col 880 .

${ }^{28}$ Harrop 'The Dynamics of Wild Animal Welfare Law' (n 19) 299) stated that 'the main issues concerning wild animal welfare law [in the UK] are always affected by...hunting with hounds'. See also Harrop, 'Wild Animal Welfare in International Law' (n 20) 382, 388.

${ }^{29}$ House of Commons Research Paper, Hunting: Wild Mammals (Protection) Bill [Bill 14 1994/95] (House of Commons Research Paper 95/26, 1995) < http://www.parliament.uk/business/publications/research/briefing_papers/RP95-26/hunting-wild-mammals-protection-bill-199495> accessed 4 August 2014.
} 
Protecting Wild Animals from Unnecessary Suffering

Nonetheless, neither this nor any other factor was given as a reason for not criminalising unreasonably caused unnecessary suffering to wild mammals. ${ }^{30}$

If it had been felt that s1 WMPA offered to wild mammals (or wild animals generally) insufficient protection from unnecessary suffering, this could have been rectified when the AWA was adopted. ${ }^{31}$ However, when what became the s 4(1) AWA offence and the s 2 AWA definition of 'protected animal', which defines the scope of that offence, were considered, truly wild animals were excluded from the scope of the s 4 unnecessary suffering offences. Once again, though, there was no explanation as to why wild animals generally (or wild mammals specifically) should not be afforded the same standard of protection from unnecessary suffering as non-wild animals. The House of Commons Environment, Food and Rural Affairs Committee noted (i) that ' $[\mathrm{t}]$ he definition [of "protected animal"] is intended to exclude wild animals, living in a wild state, from the protection of the draft Bill ${ }^{32}$ and (ii) that the Minister for Nature, Conservation and Fisheries had stated that 'the principal reason that we have not included wild animals is that they are covered by other legislation. ${ }^{33}$ The Committee then gave as examples of the existing protection for wild animals some of the offences under the Wildlife and Countryside Act 1981, as well as the s 1 WMPA offence. As such, it seems to have been implicitly accepted that the level of protection afforded to wild animals was sufficient, despite the fact that the Committee noted that the examples of offences that they gave were 'not strictly offences of cruelty: the [section 4(1)] cruelty offence would arguably have a wider application than the offences outlined above'. ${ }^{34}$ Indeed, the

\footnotetext{
${ }^{30}$ Moreover, s 2 WMPA exempts 'the killing in a reasonably swift and humane manner of any...wild mammal...injured or taken in the course of...[inter alia] lawful hunting', so it seems the desire to protect lawful hunting was adequately reflected in this exemption.

${ }^{31}$ The Hunting Act 2004 banned large-scale hunting with dogs, so the desire to avoid impinging upon lawful hunting would not have been a significant concern.

${ }^{32}$ Environment, Food and Rural Affairs Committee, The Draft Animal Welfare Bill (HC 2004-5, 52-I) [32].

33 ibid

${ }^{34}$ ibid[33].
} 
Protecting Wild Animals from Unnecessary Suffering

Committee stated that it 'support[ed] the Government's position that the protection offered by the draft Bill should not extend to wild animals, living in the wild [because] such animals are better covered by other, existing legislation. ${ }^{35}$ Once again, then, it was accepted that wild animals were afforded sufficient legal protection, but it was not explained why it was believed that they deserved less protection from unnecessary suffering than non-wild animals.

The Government response to the Committee's concerns regarding that element of the definition of 'protected animal' including animals under the permanent or temporary control of man indirectly hints at a possible moral justification for the different levels of legal protection. The Committee was concerned that, if interpreted widely, the phrase 'temporarily in the custody or control of man ${ }^{36}$ could bring truly wild animals under the protection of what became s 4(1) AWA. ${ }^{37}$ The Government responded by stating that:

\begin{abstract}
Animals living in the wild do not fall within the definition of "protected animal", so to that extent they are exempted. But we agree that the definitions become less clear when a wild animal is, for example, stranded, or trapped, or injured as in a road accident. Our approach is that once the animal is under the control of man, it is incumbent on man not to cause it, or permit it to be caused, unnecessary suffering. We do not believe that wild animals in these circumstances should be exempted. ${ }^{38}$
\end{abstract}

The Government response suggests (without making expressly clear) that an implicit reason for not affording truly wild animals the same level of legal protection from unnecessary suffering as non-

\footnotetext{
35 ibid [39].

${ }^{36}$ Which was the precursor to the phrase '[permanently or temporarily] under the control of man' as enacted in s 2 AWA.

${ }^{37}$ Environment, Food and Rural Affairs Committee (n 32) [35].

${ }^{38}$ House of Commons Environment, Food and Rural Affairs Committee, The Draft Animal Welfare Bill: Government Reply to the Committee's Report ( HC 2004-5, HC 385) [9].
} 


\section{Protecting Wild Animals from Unnecessary Suffering}

wild animals is that people owe a lesser moral duty to truly wild animals, due to the lack of control they have over such animals. It must be noted that legal and moral duties are distinct: ${ }^{39}$ a legal duty can legitimately be amoral, and it is perfectly acceptable to have no legal duty where there is a moral duty. However, it can be equally appropriate for a moral duty to form the basis of a legal duty, or the absence of a moral duty to form the basis of the absence of a legal duty; morality is not enough to make law, but it is a relevant consideration. ${ }^{40}$ Whether the greater degree of human control over non-wild animals justifies offering them greater protection from unnecessary suffering will be considered below.

In 2012, the Law Commission published a Consultation Paper relating to its project to review wildlife law in the UK. Whilst the project is mainly concerned with species-specific protections afforded to wild animals under legislation such as that noted above, consideration of the scope of protection under s 4(1) AWA and s 1 WMPA was within the remit of the project. ${ }^{41}$ Indeed, the Commission (i) proposed consolidating the s 4(1) AWA and s 1 WMPA offences under the AWA; ${ }^{42}$ (ii) reaffirmed, in its Interim Report, the view that these consolidated provisions should not be included in its proposed single piece of legislation dealing with species-specific protection; ${ }^{43}$ and (iii) suggested that the AWA 'acts in conjunction with' s $1 \mathrm{WMPA}^{44}$ and that '[t]he two Acts naturally dovetail together'. ${ }^{45}$ The Commission even stated that including in any new legislation

\footnotetext{
${ }^{39}$ Tom Regan, The Case for Animal Rights (2 $2^{\text {nd }}$ ed, University of California Press 2004) 267-71.

${ }^{40}$ Harrop 'The Dynamics of Wild Animal Welfare Law' (n 19), 289, suggests that 'animal welfare law (whether relating to wild or domestic animals)...[is] founded on moral...assumptions’ page no . See also Kimberly Smith,
} Governing Animals: Animal Welfare and the Liberal State (OUP 2012) 83

${ }^{41}$ Law Commission, (n 7) [1.20].

42 ibid [5.5], [5.21]-[5.25].

${ }^{43}$ Law Commission, Wildlife Law: Interim Statement, (2013) [1.12]. <http://lawcommission.justice.gov.uk/areas/wildlife.htm $>$ accessed 4 August 2014.

${ }^{44}$ Law Commission, Wildlife Law (n 7) [3.115]

45 ibid [5.24]. 
Protecting Wild Animals from Unnecessary Suffering

provisions replicating s 4(1) AWA and s 1 WMPA 'would...separate unnecessarily the welfare regime for all animals into wild and domesticated. ${ }^{46}$ Whilst the current s 4(1) AWA and s 1 WMPA distinction does not separate the treatment of wild and domestic animals per se, it does separate the treatment of wild and non-wild animals (according to the s 2 AWA definition of 'protected animal' and the s 3 AWA definition of responsibility for an animal). Nonetheless, despite all of these references to s4(1) AWA and s1 WMPA, the Commission did not once, in the Consultation Paper or Interim Report, mention the different levels of protection from unnecessary suffering afforded to wild and non-wild animals under the two regimes.

The Commission did state that it was 'not provisionally proposing fundamental changes to the level of protection afforded to...particular species' because such decisions 'are political and policy decisions which should be taken by the appropriate authorities, subject to scientific advice'. ${ }^{47}$ One could suggest that the same is true when considering the level of protection from unnecessary suffering afforded to wild and non-wild animals, but the Commission did not express any view on this matter. As such, it seems strongly arguable that the Law Commission did not believe there was any need even to consider whether the different standards of protection from unnecessary suffering for wild and non-wild animals was appropriate. Yet, whether this question was not considered because it was felt not to be an issue (implicitly suggesting that the current dichotomy was deemed appropriate) or because it was felt to be outside the scope of the Commission's remit (being a policy decision to be left to Parliament), it must be noted that, once again, the reasons for the different levels of protection were not addressed.

Throughout the history of the WMPA and AWA, no obvious legislative attempt has been made to justify affording wild animals less protection from unnecessary suffering than non-wild animals. The different levels of protection might be based upon an implicit belief that humans owe

\footnotetext{
46 ibid [5.5] (emphasis added).

${ }^{47} \mathrm{ibid}$ [1.25]. The Commission also stated that it 'is not concerned with value-judgements about what wildlife should be protected'. Law Commission, 'Wildlife Law: Interim Statement' (n 43) [1.7].
} 
Protecting Wild Animals from Unnecessary Suffering

a lesser moral duty to wild animals and an assumption that it is appropriate to reflect this in a lesser standard of legal protection from unnecessary suffering. However, whether this is the true basis of the different standards has not been properly addressed. Indeed, there has been no debate in the context of potential law reform as to whether the different levels of protection are justified. In the next section, it will be considered whether there are any reasons, in principle or in practice, to offer wild animals less legal protection from unnecessary suffering.

\section{$\underline{3 \text { Should Unnecessary Suffering Unreasonably Caused to Wild Animals Be an Offence? }}$}

\subsection{The Position in Principle}

Since enactment of the AWA, the law has taken a bifurcated approach to the standard of legal protection from unnecessary suffering ${ }^{48}$ afforded to non-wild animals. On the one hand, it is, under s 4(1) AWA, an offence for any person unreasonably to cause unnecessary suffering to a protected animal; on the other, ss 4(2) and 9 AWA require those responsible for an animal to take reasonable steps to ensure (i) that another person does not cause unnecessary suffering to the animal (s 4(2)) and (ii) that the animal's needs are met to the standard required by good practice (s 9). By virtue of s 3 AWA, the owner of an animal is always deemed legally responsible for that animal, as is anyone who is in charge of the animal, whether on a permanent or temporary basis. ${ }^{49}$

It is submitted that, whether or not one believes the legal standards imposed are appropriate, this basic distinction in the level of protection afforded to non-wild animals is logical, requiring more from people in relation to any animal(s) for which they are legally responsible. The question becomes whether a further distinction should apply to wild animals. That is to say, should the law

\footnotetext{
${ }^{48}$ The AWA contains specific protections against, e.g., mutilation, tail-docking of dogs, poisoning, and animal fighting: see ss 5-8 AWA.

${ }^{49}$ If a child under the age of 16 is responsible for an animal, any person who has actual care and control of the child is also deemed legally responsible for the animal: s 3(4) AWA.
} 
Protecting Wild Animals from Unnecessary Suffering

require from a person the strictest duty to animals for which s/he is responsible, an intermediate duty to domesticated animals and animals under another person's control, and the least strict duty to wild animals? Alternatively, should wild animals be treated in the same way as domesticated animals and those under human control, at least insofar as the general standard of protection from unnecessary suffering is concerned?

Before dealing with this issue, a preliminary point must be addressed. At present, truly wild non-mammalian species receive no protection from unnecessary suffering per se. ${ }^{50}$ Legal protection from unnecessary suffering should surely be based primarily upon the ability of a sentient animal to suffer, ${ }^{51}$ and scientific evidence very strongly suggests that many non-mammalian species are equally capable as mammals of suffering. ${ }^{52}$ Indeed, since its inception, the Animals (Scientific Procedures) Act 1986 has applied to non-mammalian vertebrates and now even extends to cephalopods (which are a form of invertebrate, and thus obviously non-mammalian, animal). Moreover, scientific evidence as to the ability of non-mammalian vertebrates to suffer has been sufficient to ensure that these types of animal are included in the scope of the AWA, and it is suggested that the same approach should be taken to the s 1 WMPA offence. ${ }^{53}$

Given that many different wild animals (in this sense, 'wild animal' simply means an animal of a kind which is not commonly domesticated in Britain) are in captivity, or at least sufficiently under the control of man to fall under the s 4(1) (and often the ss 4(2) and 9) AWA protection, but are clearly not of a kind commonly domesticated in the British Islands, the distinction which currently exists in the standards of protection afforded to wild mammals under s 1 WMPA and protected animals under s 4(1) AWA is clearly not based upon domestication. Whilst many humans

\footnotetext{
${ }^{50}$ Although, some benefit from species-specific protections.

${ }^{51}$ Schaffner (n 18) 10, and Harrop, ‘The Dynamics of Wild Animal Welfare Law' (n 19) 296.

${ }^{52}$ Harrop (n 19) 300 suggested that, perhaps, 'the law... will turn to science as the ultimate arbiter in deciding questions of wild animal welfare', in the sense of determining which animals can suffer and which activities cause them to suffer. ${ }^{53}$ ie, the provision should cover all wild vertebrates (other than man) not in foetal or embryonic form.
} 


\section{Protecting Wild Animals from Unnecessary Suffering}

undoubtedly have a stronger emotional connection to animals of commonly domesticated species, the law does not recognise domestication per se as grounds for greater protection from unnecessary suffering. For the same reason (ie that many different types of wild animals ${ }^{54}$ are under the control of man), the distinction is also clearly not based upon any inherent physiological differences ${ }^{55}$ between truly wild animals, on the one hand, and domesticated animals and animals under human control, on the other. The basic physiology of an animal obviously does not change simply because that animal comes under the control of man.

A distinction which might make a difference to the standard of legal protection afforded to animals is ownership. Although there exist certain property rights to take or kill wild animals (in accordance with the protection afforded to various species under, eg, the Wildlife and Countryside Act 1981) on one's land (and potentially elsewhere), truly wild animals are not generally viewed as property. ${ }^{56}$ However, captive animals, whether originally wild or not, are generally legally viewed as property. ${ }^{57}$ It is obvious that certain legal consequences must flow from the status of an animal as property, such as, for example, the possibility of tortious damages for the owner when the animal property is damaged. Indeed, historically, an animal's status as property was capable of affording

\footnotetext{
${ }^{54}$ In this sense, 'wild animal' again simply refers to an animal of a non-domesticated species.

${ }^{55}$ Physiological differences would be relevant to protection from unnecessary suffering if they had an impact upon an animal's ability to suffer.

${ }^{56}$ Jeremy Bruskotter, Sherry Enzler and Adrian Treves, 'Rescuing Wolves from Politics: Wildlife as a Public Trust Resource' (2011) 333 Science 1829 suggest that, in the US, the status of wildlife as property belonging in trust to all citizens. See also Smith, (n 40) 71 could be used to impose on State governments (the 'trustees') a duty to seek to maintain species populations.

${ }^{57}$ Radford (n 9)100. For a general summary of the law's treatment of animals as property, see 99-105. Arguments as to whether the status of animals as property should change see Steven Wise, Rattling the Cage: Toward Legal Rights for Animals (Perseus 2000) and Steven Wise, Drawing the Line: Science and the Case for Animal Rights (Perseus2002) and Smith, (n 40) 70-98 are outside the scope of this article.
} 
Protecting Wild Animals from Unnecessary Suffering

the animal some protection from suffering. ${ }^{58}$ If someone caused suffering to an animal without the owner's consent, that person could potentially be guilty of criminal damage and liable in tort. Yet such laws afforded animals no protection against their owners. Writing in 1796, John Lawrence stated that 'no man is punishable for an act of the most extreme cruelty to a brute animal but upon the principle of an injury done to the property of another...[and] the owner...has the...allowance of the law to inflict upon it...the most horrid barbarities. ${ }^{59}$ Similarly, as Radford notes,

the owner of an animal might bring proceedings against a third party who had injured or abused it..., but the owner himself could treat it howsoever he pleased, and authorize his employees likewise... On the same principle, wild animals, with no permanent property interest for the courts to protect, were even more vulnerable. ${ }^{60}$

Whatever the historical position, the law has developed to afford animals protection from unnecessary suffering regardless of their status as property. For example, the anti-cruelty measures of the mid-1800s, ${ }^{61}$ which were consolidated and extended by the Protection of Animals Act 1911, applied the offence of cruelty to include the actions of an owner, and even rendered an owner criminally liable if s/he, for example, permitted unnecessary suffering to be wantonly or unreasonably caused to his/her animal. ${ }^{62}$ Moreover, the cruelty offences under the 1911 Act were capable of applying even to animals that were not owned by anyone, ${ }^{63}$ and the same is true under the AWA ${ }^{64}$ In particular, any animal of a domesticated species which is not owned by a person

\footnotetext{
${ }^{58}$ Radford (n 9) 29.

${ }^{59}$ John Lawrence, 'On the Rights of Beasts', in A Philosophical and Practical Treatise on Horses, and on the Moral Duties of Man towards the Brute Creation (Longman1796) 123.

${ }^{60}$ Radford (n 9) 101.

${ }^{61}$ eg the Prevention of Cruelty to Animals Act 1849.

62 s 1(1)(a) Protection of Animals Act 1911.

63 ibid s 15.

${ }^{64}$ ss 1,2 and 3 AWA.
} 
Protecting Wild Animals from Unnecessary Suffering

nonetheless falls within the protection of section 4(1) AWA. As such, protection from unreasonably caused unnecessary suffering is not based upon the status of an animal as property.

Of course, the level of legal protection afforded to an animal is affected by the animal's status as property, because, as highlighted above, an owner of an animal does owe a duty to take reasonable steps (i) to provide for that animal's needs according to good practice ${ }^{65}$ and (ii) to prevent another person from causing unnecessary suffering to the animal ${ }^{66}$ However, these are issues related to the promotion of animal welfare and responsible animal ownership; they are not concerned with the basic protection of animals from unnecessary suffering.

It could be argued that financial factors are relevant to accepting a lesser standard of protection for wild animals. For example, perhaps criminalising unreasonably caused unnecessary suffering might stifle significant economic activity (such as, say, lawful hunting, property development or pest control), as fewer people might engage in these activities if they could become criminally liable for unnecessary suffering unreasonably caused to wild animals whilst participating in a particular activity. However, it is contended that, given the inherent value (financial as well as environmental) of all forms of wildlife, careful, responsible interactions with nature should be promoted. Offering wild animals the same level of protection from unnecessary suffering as nonwild animals (and thus criminalising unreasonably caused unnecessary suffering to wild animals) would serve this purpose and sit well with the global trend of promoting respect for the natural environment.

One can argue that individuals should owe a lesser legal duty to truly wild animals than to those under the control of man (including all animals of domesticated species), on the basis that greater human control of an animal places a greater moral $^{67}$ duty on human society (and its individual members) to care for an animal, in part because of the animal's vulnerability to, perhaps

\footnotetext{
65 s 9 AWA.

66 ibid s 4(2).

${ }^{67}$ See above for discussion of the relationship between legal and moral duties.
} 
Protecting Wild Animals from Unnecessary Suffering

even dependence on, humans and in part due to human interference with the animal's freedom.

Indeed, Smith asserts that, in part because they are not under human control, 'most wild animals are properly treated as outside the social contract. ${ }^{, 68}$

Certainly, it is legitimate for a person to owe a lesser legal duty to an animal for which s/he is not responsible than to an animal for which s/he is responsible, because the elements of control (in the person) and vulnerability (in the animal) inherent in responsibility are sound bases for imposing greater legal duties to ensure greater legal protection. However, this is already reflected in the $\mathrm{s} 4(1) / \mathrm{s} 9$ AWA distinction, which is a distinction between prevention of unnecessary suffering and promotion of welfare. Moreover, the law already recognises that the fact that no human is responsible for an animal does not justify offering that animal less protection from unnecessary suffering, as animals of commonly domesticated species for which no person is responsible still fall within the s 2 AWA definition of 'protected animal' and thus come within the scope of s 4(1). As such, the question becomes whether the elements of control and vulnerability implicit in domestication (and existing when animals of wild species are under the control of man), and not present so strongly in relation to truly wild animals, justify affording wild animals less protection from unnecessary suffering. Perhaps it is felt that a greater moral duty to non-wild animals, founded primarily upon human control and animal vulnerability, does justify imposing greater legal protection from unnecessary suffering. If this is the case, it should be clearly recognised as the foundation of the legal distinction, to open up the possibility of informed debate to determine whether society accepts such an argument.

The preceding analysis suggests that the argument that people should owe a greater moral duty to domesticated animals and animals under human control is the only potentially sound basis in principle for affording wild animals less legal protection from unnecessary suffering than the

\footnotetext{
${ }^{68} \mathrm{Smith}(\mathrm{n} 40) 62$. Smith suggests that human society generally owes a greater moral duty to domesticated animals and other animals under human control: 35-70, 104. See also, Paul Waldau, Animal Rights: What Everyone Needs to Know (OUP 2011) 50-53.
} 
Protecting Wild Animals from Unnecessary Suffering

former categories of animals. Yet such an argument has never been clearly and openly addressed, so it is not clear whether it has been, or (if so) would continue to be, widely accepted by society, experts and decision-makers. This issue should be openly addressed to determine whether the law in this area should be reformed, affording wild animal equal protection from unnecessary suffering.

If it is believed that wild and non-wild animals should be afforded equal protection from unnecessary suffering, the appropriate standard must be considered. For over a century, non-wild animals have been protected from unreasonably caused unnecessary suffering, ${ }^{69}$ and no sound argument in favour of reducing the level of protection has been made. Moreover, to extend this level of protection to wild animals would promote respect for, and careful, responsible interactions with, the environment. Therefore, if it is believed that wild and non-wild animals should receive equal protection from human-caused unnecessary suffering, the appropriate standard is to protect them from any unreasonably caused unnecessary suffering.

By virtue of s 4(1) AWA, this proposed standard is applicable to domesticated animals and animals under human control, and the analysis above suggests that it would be appropriate to provide wild animals the same degree of protection from unnecessary suffering as is afforded to the former categories of animals. As such, it is contended that s 4(1) should be extended to apply to wild animals. In addition to the above arguments in favour of equal protection for wild animals, it will be contended that s 4(1) shares a similar purpose, and has similar rules, to the tort of negligence, and that these similarities (i) provide some additional support for extending s 4(1) to wild animals and (ii) enable detailed consideration of how an extended offence would apply.

Section 4(1) requires a minimum standard of care in one's conduct whenever it is reasonably foreseeable that such conduct might cause unnecessary suffering to a protected animal, thereby affording these animals a basic level of protection from harm. Although negligence is a complex area of law, covering such disparate issues as the negligence of public authorities, ${ }^{70}$ medical

\footnotetext{
${ }^{69}$ eg s 1 Protection of Animals Act 1911 and s 4(1) AWA.

${ }^{70}$ Stovin v. Wise [1996] AC 923.
} 


\section{Protecting Wild Animals from Unnecessary Suffering}

negligence, ${ }^{71}$ pure economic loss, ${ }^{72}$ occupiers' liability, ${ }^{73}$ nervous shock, ${ }^{74}$ personal injury ${ }^{75}$ and property damage,${ }^{76}$ and dealing with liability for omissions ${ }^{77}$ and commissions,${ }^{78}$ a person's general negligence-based tortious duty is to refrain from unreasonably causing damage to another's person or property, with one being liable for the damage when it was reasonably foreseeable that one's actions might cause such damage to a person of a class to which the claimant belonged. ${ }^{79}$ As such, the law of negligence similarly requires a minimum standard of care whenever it is reasonably foreseeable that one's conduct might injure another, thereby protecting people from injury. ${ }^{80}$ In addition to these shared purposes and effects, the levels of protection afforded by negligence and s 4(1) are extremely similar. Section 4(1) requires proof (i) that the defendant's act or omission caused a protected animal to suffer unnecessarily and (ii) that s/he 'knew, or ought reasonably to have known, that the act, or failure to act, would have that effect or be likely to do so'. The basic requirement of a duty of care in negligence is that it was reasonably foreseeable that the defendant's conduct might injure the claimant (individually or as member of a class). ${ }^{81}$ The duty

\footnotetext{
${ }^{71}$ Bolam v. Friern Hospital Management Committee [1957] 1 WLR 582.

${ }^{72}$ Hedley Byrne v. Heller [1964] AC 465; Caparo Industries v. Dickman [1990] 2 AC 605.

${ }^{73}$ Wheat v E Lacon v. Co Ltd [1966] AC 552.

${ }^{74}$ Vernon v. Bosley (No. 1) [1997] 1 All ER 577.

${ }^{75}$ Whippey v. Jones [2009] EWCA Civ 452.

${ }^{76}$ Northumbrian Water Ltd. V. Sir Robert McAlpine Ltd [2014] EWCA Civ 685.

${ }^{77}$ Reeves v. Commissioner for the Metropolis [2000] 1 AC 360.

${ }^{78}$ Bolton v. Stone [1951] AC 850.

${ }^{79}$ Hayley v. London Electricity Board [1965] AC 778.
}

${ }^{80}$ The comparison with negligence in this article is concerned with those principles of negligence applicable to personal injury claims, as the nature of the harms in these cases are similar to those in s 4(1) AWA cases. Issues directly relevant only to, for example, occupiers' liability, medical negligence, negligence by public authorities, nervous shock or pure economic loss are not apposite, as they are affected by policy considerations specific to those areas of the law.

${ }^{81}$ A duty of care obviously requires more than mere reasonable foreseeability of harm (e.g., Caparo Industries $v$. Dickman [2002] 2 AC 605). However, in personal injury cases, policy and proximity issues do not play a significant 
Protecting Wild Animals from Unnecessary Suffering

of care under s 4(1) applies in the same circumstances, because the provision requires proof that the defendant 'knew, or ought reasonably to have known, that [his/her conduct] would [cause a protected animal to suffer unnecessarily] or be likely to do so'. A breach of duty in negligence consists of engaging in conduct which was unreasonable, given the existence of the duty. ${ }^{82}$ Breach of s 4(1) likewise requires that the defendant engages in conduct which causes an animal to suffer unnecessarily, when s/he knew or should have known that this would, or would likely, be the consequence of such conduct. If the defendant actually knew of the risk, s/he was reckless.

However, it is contended that, even if the defendant was not aware of the risk, his/her conduct was unreasonable, for two related reasons. First, the reasonable person would have appreciated the risk. Second, whilst it is not always unreasonable to run a risk which the reasonable person would have foreseen, unnecessary suffering is suffering which could reasonably have been avoided, ${ }^{83}$ and it is unreasonable to cause a harm which the reasonable person would have foreseen and which could reasonably have been avoided. Finally, negligence requires that the defendant's breach caused harm to the claimant that was not too remote: ie., harm of a type which was the reasonably foreseeable consequence of the defendant's action. ${ }^{84}$ The requirements under s $4(1)$ that the defendant's conduct caused an animal to suffer unnecessarily and that s/he 'knew, or ought reasonably to have known,

role; reasonable foreseeability of personal injury will be sufficient to establish the duty, absent compelling policy reasons (e.g., Hayley v. London Electricity Board [1965] AC 778). This is crucial because (i) unnecessary suffering is clearly directly analogous to personal injury and (ii) the above analysis has argued that there are no compelling policy reasons not to extend s $4(1)$, and thereby the duty of care it creates, to wild animals.

${ }^{82}$ Whippey v. Jones [2009] EWCA Civ 452.

${ }^{83} \mathrm{~s} 4$ (3) AWA. Although this is only a relevant, not necessarily conclusive, element, it is difficult to see how suffering which could not reasonably have been avoided could be deemed legally unnecessary. Under the 1911 Act, suffering would only be legally unnecessary if it could not reasonably have been avoided. See Hall \& Hall v. RSPCA (QBD, unreported, 11th November 1993).

${ }^{84}$ The Wagon Mound (No.2) [1967] 1 AC 617. 


\section{Protecting Wild Animals from Unnecessary Suffering}

that [his/her conduct] would have that effect or be likely to do so' mirror these elements of negligence, ensuring that the defendant's conduct causes harm which was not too remote.

One can see that there are strong similarities between negligence and s 4(1) AWA, similarities which exist both in the essential purposes of the rules and in the details of those rules. None of this would change with extension of the provision to cover wild animals: the basic duty of care would apply when it was reasonably foreseeable that the defendant's conduct might cause unnecessary suffering to an animal, and that duty would be breached by the defendant unreasonably engaging in conduct which actually causes unnecessary suffering which was the reasonably foreseeable (ie not too remote) consequence of that conduct. Indeed, it is contended that comparison of s 4(1) and negligence offers some support for extending s 4(1) to wild animals, because the links between the two areas of law are equally strong when applied to wild animals. ${ }^{85}$ Nonetheless, even if one does not accept the comparison, this can be separated from the argument, addressed above, as to whether wild animals should be afforded equal protection from unnecessary suffering.

In addition to potentially providing support for the contention that s 4(1) should be extended to protect wild animals, comparison between s 4(1) and negligence helps with consideration of how the offence would apply to wild animals if extended. In particular, the comparison helps with analysis of whether an extended s 4(1) should apply to omissions, and whether it should require that it was at least reasonably foreseeable (i) simply that an animal (of any kind protected by s 4(1), as extended) would, or would likely, suffer; (ii) that a wild animal would suffer; or (iii) that a wild animal of a particular species would suffer. These issues will be addressed in turn.

\footnotetext{
${ }^{85}$ It has already been explained that s 4(1) applies regardless of whether the defendant has any control over, or responsibility for, the animal which his/her actions cause to suffer unnecessarily, as the offence applies equally to domesticated animals over which no person has control. Therefore, the fact that the defendant lacks control over, or responsibility for, a truly wild animal is no reason to exclude the duty of care, if it is reasonably foreseeable that the defendant's actions will cause, or are likely to cause, unnecessary suffering.
} 
Protecting Wild Animals from Unnecessary Suffering

It could be argued that there should be a distinction between the duty owed by a person (i) to wild animals and (ii) to domesticated animals and animals under human control, reflecting the existing distinction in the law of negligence between the duty owed (i) to strangers and (ii) to people towards whom one has assumed responsibility (such as, for example, by undertaking a rescue attempt). It can be said that domestication and/or human control over an animal is an assumption of responsibility by human society and its individual members, whereas no such responsibility is assumed to truly wild animals. Under the law of negligence, if one has assumed responsibility to another, one has a duty not to act unreasonably so as to cause (reasonably foreseeable) injury and a duty to act reasonably to prevent (reasonably foreseeable) injury which one did not cause. ${ }^{86}$ On this basis, domestication and/or human control over an animal would place a positive duty on society and its individual members (i) to act reasonably so as not to cause, and (ii) not unreasonably to fail to act so as to cause, injury (unnecessary suffering) to these animals. This duty is reflected in s 4(1) AWA and is incumbent upon every person in relation to all protected animals.

Continuing with this reasoning, wild animals would fall into the category of 'strangers'. Under the law of negligence, one generally does not have a positive duty to engage in actions to prevent injury to a stranger: that is to say, one is not liable for pure omissions. ${ }^{87}$ Yet one still has the duty not to act in such a way as unreasonably to cause injury to a stranger, if it was reasonably foreseeable that one's actions might cause that type of injury to that class of person. ${ }^{88}$ With the exception of imposing liability on the basis of omissions, this is all that s 4(1) AWA requires. As such, the present analogy can justify not extending liability for unnecessary suffering caused to wild

\footnotetext{
${ }^{86}$ Reeves v. Commissioner for the Metropolis [2000] 1 AC 360.

${ }^{87}$ Maloco v. Littlewoods Organisation Ltd. [1981] AC 241, 271, per Lord Goff.

${ }^{88}$ Hayley v. London Electricity Board [1965] AC 778, Whippey v. Jones [2009] EWCA Civ 452 (as to duty of care and breach); The Wagon Mound (No.2) [1967] 1 AC 617 (as to remoteness of damage).
} 
Protecting Wild Animals from Unnecessary Suffering

animals by an unreasonable omission, but it actually supports extending the provision to protect wild animals from unnecessary suffering caused by positive actions.

If s 4(1) AWA is to be extended to cover wild animals, it is necessary to determine whether the extended offence should require proof that the defendant knew, or ought reasonably to have known, of at least the likelihood (i) simply that an animal, wild or non-wild, would suffer, (ii) that a wild animal would suffer, or (iii) that a particular species of wild animal would suffer. Assume that a person disposed of a substance and knew, or ought reasonably to have known, that it was likely that a non-wild animal would come into contact with the substance and suffer unnecessarily, but s/he did not know, and the reasonable person would not have known, that this risk extended to wild animals. Alternatively, adapting the example, assume that the defendant knew, or ought reasonably to have known, of the risk to a particular species of wild animal but did not know, and the reasonable person would not have known, of the risk to a different species of wild animal. Reverting to the analogy with the law of negligence, it could be argued that the defendant should not have a duty of care in either case because the type of 'victim' (a wild animal, or the particular species of wild animal) was not reasonably foreseeable.

It is not clear whether a similar limitation is inherent in the elements of the current s 4(1) offence. For example, if the reasonable person would have known only that the defendant's actions would be likely to cause (i) a cat to suffer, but a dog actually suffered unnecessarily, or (ii) an animal of a domesticated species to suffer, but a protected animal not of a domesticated species suffered, would the offence be committed? On the one hand, it can be argued that the defendant has taken an unreasonable risk and a protected animal has suffered, so the protective focus of s 4(1) should be invoked and an offence should have been committed. Moreover, the language of that provision requires simply that $a$ protected animal suffered unnecessarily and that the defendant had actual or constructive knowledge that his actions would have, or would be likely to have, that effect (ie., to cause $a$ protected animal to suffer). On the other hand, it can be argued that allowing liability in such situations would impose criminal liability for an objectively unforeseeable risk. 
Protecting Wild Animals from Unnecessary Suffering

It is of course unlikely that any person would appreciate that an animal of a particular type (eg domesticated as opposed to non-domesticated, or wild as opposed to non-wild) or species would be likely to be suffer but would not appreciate that an animal of a different type or species would be likely to suffer, because most actions which are objectively obviously harmful to one type or species of animal would be equally objectively obviously harmful to most other types or species falling within the definition of animals under s 1 AWA. Therefore, this difficult issue is unlikely to pose significant practical problems. Nonetheless, the issue could arise,${ }^{89}$ so a decision on the application of the section must be made.

In the law of negligence, one cannot be liable to another if it was not reasonably foreseeable that one's actions might cause injury to that other, individually or as member of a class. For example, in Hayley v. London Electricity Board,$^{90}$ the House of Lords accepted that the defendant would not have been liable to the claimant (a blind man) if it had not been reasonably foreseeable that he might have been injured by the defendant's actions. Therefore, it is contended that, as it would apply to truly wild animals, ${ }^{91}$ an extended s 4(1) offence should require proof that the defendant at least should have known that it was likely his conduct would cause suffering to an animal of the particular species which suffered unnecessarily, because there would be no duty of care to an animal of a species which it was not at least reasonably foreseeable might be harmed by the defendant's conduct. ${ }^{92}$

\footnotetext{
${ }^{89}$ For example, it is known that chocolate is potentially harmful to cats and dogs, but there is insufficient evidence to determine whether it is harmful to many other species of animals. Similarly, the defendant might have seen a particular species of wild animal (say, a fox) in his garden, where he leaves an easily accessible dangerous substance, but not know that there is a realistic possibility of a different species (say, a badger) entering the garden.

${ }^{90}[1965]$ AC 778.

${ }^{91}$ Whether a similar limitation should apply to the present s 4(1) offence should be determined, but that question is outside the scope of this article.

92 The limitation as to foreseeability of victim should apply on the basis of species because different species can properly be regarded as different classes of 'victim'.
} 
Protecting Wild Animals from Unnecessary Suffering

It is accepted that one can make a strong counter-argument that the protective purpose of $s$ 4(1) AWA should ensure that it is sufficient to prove that the defendant's unreasonable actions caused an animal (of any kind covered by s 4(1), as it stands and if extended to cover wild animals) to suffer unnecessarily and s/he knew or should have known that an animal protected by the provision would suffer or would be likely to suffer. This would be a policy decision to promote animal protection which could be legitimately taken but which would have to be expressly recognised and justified.

Another issue raised by the comparison between s 4(1) and negligence is the fact that s 4(1) is concerned with criminal sanctions, rather than financial compensation in a civil suit, and criminal liability is not normally imposed on the basis of 'mere', as opposed to 'gross' negligence. ${ }^{93}$ However, criminal liability for causing unnecessary suffering to a non-wild animal has long been based upon objectively unreasonable conduct. Section 1 of the Protection of Animals Act 1911 rendered it a crime 'unreasonably [to do] or omit to do any act...[which] cause[d] any unnecessary suffering' to an animal protected by the Act. The Divisional Court in Hall \& Hall v. RSPCA ${ }^{94}$ confirmed that 'unreasonably' meant 'objectively unreasonably', so that there was no need to prove that the defendant knew his conduct would have been deemed unreasonable by the reasonable person. ${ }^{95}$ Moreover, even though mere negligence is not normally seen as providing sufficient mental culpability to justify criminal sanctions,${ }^{96}$ imposing criminal liability on this basis under s 4(1) AWA (as it currently stands and as it would stand if expanded to cover wild animals) would not be inappropriate in principle. One might argue that merely negligent actions are not sufficiently

${ }^{93} R$ v. Adomako [1995] 1 AC 171.

${ }^{94}$ QBD, unreported, 11th November 1993.

95 The 1911 Act did not expressly require proof that the defendant knew or ought reasonably to have known of the likely consequences of his actions (a requirement under s 4(1) AWA which has been shown to mirror the duty of care and remoteness requirements of personal injury negligence claims), but it is arguable that this was inherent in the explicit requirement under the 1911 Act that the defendant's conduct be proved unreasonable.

${ }^{96}$ Claire Finkelstein, 'Responsibility for Unintended Consequences' (2004) 2 Ohio State J of Crim L 579. 


\section{Protecting Wild Animals from Unnecessary Suffering}

morally blameworthy to justify criminal sanctions, but it must be remembered that the law here is primarily concerned with protecting from unnecessary suffering animals who are, in a sense, inherently vulnerable to humans. Therefore, the law is serving one of its fundamental purposes: protecting the vulnerable from abuse. The use of criminal sanctions, with their stigmatising and deterrent effects, strengthens this protection, and to prohibit only intentionally (or recklessly) caused unnecessary suffering would be to dilute greatly the protection offered. As such, it is submitted that the need to protect animals (wild and non-wild) can justify imposing criminal liability on the basis of objectively unreasonable conduct (mere negligence). White suggests that US 'courts have become increasingly willing to allow criminal penalties for certain acts of ordinary negligence which can be considered public welfare offenses' ${ }^{97}$ Such developments (which she does not fully support) are based upon seeking to uphold the protective focus of the relevant legislation, and a direct analogy can be drawn with the protective focus of the AWA and extension of s 4(1) of that Act to cover wild animals.

As noted above, historically, animal protection law was (at least overtly) concerned more with regulating human conduct for the sake of human society than with protecting animals for their own sake. ${ }^{98}$ It could be suggested that a concern to regulate human behaviour for purposes other than protection of animals is reflected in the s 1 WMPA requirement of proof of intent to inflict unnecessary suffering, which might then call into question extending to wild animals the more protective s4(1) AWA prohibition of unreasonably caused unnecessary suffering. However, there are many legislative provisions that clearly demonstrate that animal protection legislation in general is now primarily concerned with protecting animals for their own sake. For example, the s 1 AWA definition of 'animal' ${ }^{99}$ bases the scope of animals protected by the Act on scientific evidence as to

\footnotetext{
${ }^{97}$ Tanya White, 'Taking Criminal Liability of Negligent Actors One Step too Far' (1999) 7 Missouri EnvL and Policy Rev 104, 104.

${ }^{98}$ Radford (n 9) 15-95.

${ }^{99}$ Vertebrates other than man, not in their foetal or embryonic form.
} 


\section{Protecting Wild Animals from Unnecessary Suffering}

the types of animal which can suffer and expressly gives the Secretary of State power to extend the definition in certain ways, ${ }^{100}$ but only if s/he 'is satisfied, on the basis of scientific evidence, that animals of the kind concerned are capable of experiencing pain or suffering'; s 9 AWA goes beyond the need to prove suffering before an offence is committed, imposing a welfare duty requiring people to take reasonable steps to provide for the needs of animals for which they are responsible; and Art 13 of the Treaty on the Functioning of the European Union expressly recognises the sentience of animals.

Of course, nothing in these provisions suggests that the main concern of s 1 WMPA is, or should be, protection of animals per se. Indeed, the fact that the offence does not actually require proof of unnecessary suffering, instead requiring proof of an intent to inflict unnecessary suffering, ${ }^{101}$ supports the contention that it is more concerned with regulating human conduct and thus has a less protective focus. Yet this does nothing more than beg the question as to why the law is more concerned to regulate human behaviour towards wild animals than to protect the animals themselves, which is itself nothing more than a different way of asking whether there is any justification for offering wild animals less protection from unnecessary suffering. This question has already been addressed above. In short, any argument that protection of vulnerable animals is not the primary focus of s 1 WMPA does nothing to suggest that a more protective focus would be inappropriate.

In summary, it is contended that it would be appropriate in principle to extend s 4(1) AWA to wild animals, subject to the points noted above regarding (i) not extending liability for an unreasonable omission and (ii) requiring proof that the defendant knew or should have known of the likelihood of his actions causing suffering to an animal of the particular species which suffered unnecessarily. This would leave the original s 1 AWA definition of animal (vertebrate other than

\footnotetext{
100 ie to include invertebrates and vertebrates from any stage of their development.

${ }^{101}$ It has been noted above that unnecessary suffering will almost always have been inflicted when the offence is committed.
} 
Protecting Wild Animals from Unnecessary Suffering

man, not in a foetal or embryonic state) as defining the limits of animals protected from unreasonably caused unnecessary suffering.

\subsection{The Position in Practice}

If it is deemed acceptable in principle to extend s 4(1) AWA to wild animals, it must be considered whether extension is appropriate in practice. In this regard, there are two key questions that must be considered. The first is whether extension would create too severe a burden on people, hindering too many legitimate activities. For example, it could be suggested that extension might cause problems for people engaged in legitimate activities such as lawful pest control or hunting, rendering them subject to potential liability that would inhibit their involvement in such activities. It is submitted that the standards of reasonableness and necessity (as the offence requires unreasonable conduct which caused unnecessary suffering) dictate that this fear is unfounded.

Section 4(3) AWA specifically states that 'whether...suffering could reasonably have been avoided or reduced' is a relevant consideration in determining whether it was 'unnecessary'. Although this is only a relevant consideration, it is difficult to see how suffering which could not reasonably have been avoided could be legally unnecessary. Moreover, the definition of 'unnecessary suffering' under s 4(3) AWA states that it is relevant to have regard to, inter alia, 'whether the conduct which caused the suffering was in compliance with any relevant enactment or any relevant provisions of a licence or code of practice issued under an enactment' and 'whether the conduct which caused the suffering was for a legitimate purpose, such as...the purpose of protecting a person, property or another animal'. Under the former consideration, the fact that the defendant was engaging in, say, lawful hunting or lawfully performing some other legally regulated activity 
Protecting Wild Animals from Unnecessary Suffering

would be relevant; under the latter, the fact that s/he was engaging in, eg legitimate pest control or some other legitimate protective activity would be relevant. ${ }^{102}$

To be a s 4(1) AWA offence, any unnecessary suffering must have been (i) actually foreseen by the defendant as at least the likely consequence of his/her conduct or (ii) a consequence which s/he 'ought reasonably to have known' was at least the likely consequence of his/her conduct. Therefore, one cannot be liable if the reasonable person would not have appreciated the risk (unless one actually appreciated the risk when the reasonable person would not have). Similarly, one could not be liable if there were no reasonable precautions which could have been taken to eradicate or reduce the risk, because any suffering caused would not be legally unnecessary.

A reasonableness-based duty to avoid inflicting unnecessary suffering on domesticated animals and other animals under human control, enforced with the threat of criminal sanctions, including imprisonment, has not been seen as too burdensome in the many years it has applied, and there is no reason to think that extension of the duty to cover wild animals would be unduly burdensome in practice, particularly given the limits as to foreseeability and liability for omissions discussed above.

The second important question to address in determining whether extension of s 4(1) AWA to cover wild animals is appropriate in practice is whether the hypothetical reasonable person's level of knowledge of the way in which wild animals can suffer is sufficient to render the extension useful, or whether it is so low that it would be rare for the court to determine that the defendant at least should have known that his/her conduct was likely to cause an animal to suffer when s/he did not intend to inflict unnecessary suffering on a wild animal, so that the extended offence would have little effect in practice. Therefore, it is necessary to consider the ways in which the average person's actions can harm wild animals. The most obvious scenario is disposal of potentially harmful substances or other items in a fashion that poses a risk of a wild animal coming into contact

\footnotetext{
${ }^{102}$ If the pest control included use of any poison or other injurious substance, it would have to comply with s 7 AWA and s 8 Protection of Animals Act 1911.
} 


\section{Protecting Wild Animals from Unnecessary Suffering}

with the substance or item. In this regard, it should be noted that s 7 AWA renders it an offence for anyone 'without lawful authority or reasonable excuse' ${ }^{\text {103 }}$ to administer to, or cause to be taken by, a protected animal 'any poisonous or injurious drug or substance' in the knowledge that the substance is poisonous or injurious. The explanatory notes to the AWA make it clear that 'the term “administer" should be understood as indicating a deliberate action.' ${ }^{104}$ Moreover, although causing an animal to take a poisonous or injurious substance does not necessarily connote deliberate action in the same way that administering it does, the explanatory notes expressly state that '[a]ccidental poisoning will not be caught by section $7^{, 105}$. Therefore, this provision seems to prohibit only intentional actions done with knowledge of the potentially harmful nature of those actions.

However, it should not be thought that the scope of s 7 AWA demonstrates that Parliament did not intend unreasonable poisoning, etc., of even a protected animal to be an offence, when that action causes an animal to suffer unnecessary. If this were the case, it would of course call into question extension of s 4(1) AWA to criminalise unreasonable accidental poisoning of wild animals. The crucial fact to note is that $\mathrm{s} 7$ renders the administration, etc., an offence regardless of whether an animal suffers. The absence of any requirement to prove suffering arguably renders the need for intentional administration, etc., justifiable. Whether one agrees with this or not, the absence of the need to prove suffering ensures that the intentionality requirement of s 7 cannot be used to undermine extension of s4(1) AWA in a way which would potentially criminalise unreasonable poisoning of a wild animal when it is actually proved that the animal suffered unnecessarily.

\footnotetext{
${ }^{103}$ Lawful pest control in accordance with, inter alia, s 8 Protection of Animals Act 1911 would be exempted by virtue of this element of the offence.

104 ‘Animal Welfare Act 2006 - Explanatory Notes’ [37]

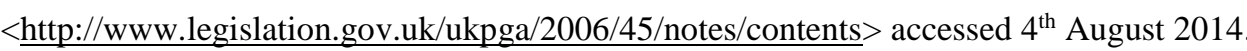

105 ibid.
} 
Protecting Wild Animals from Unnecessary Suffering

Returning to consideration of how improper disposal of potentially harmful substances or other items would amount to an offence under an extended s 4(1) AWA, assume that a person (the defendant) disposes of, for example, paints, petrol, motor oil, bleach, chemical cleaners (or any of the other myriad of obviously potentially harmful substances found in the majority of homes), and does so in such a way that the reasonable person would know that it was likely that a (or some) species of wild animal would come into contact with the substance. Further assume that such a wild animal does come into contact with it and suffers. Surely, the animal's suffering would be unnecessary, because it could reasonably have been avoided (provided that there was a reasonable way of disposing of the substance in a manner which would have minimised or eradicated the risk of the animal coming into contact with it). Similarly, the defendant surely at least should have known that his/her actions would at least be likely to cause a wild animal of that species to suffer, because the substance was one which was obviously potentially harmful, and the reasonable person would have known that it was likely that a wild animal of that species would come into contact with the substance and suffer because of the way the substance was disposed. If the animal which came into contact with the substance and suffered was a cat or dog, but all other facts were the same, an offence would clearly be committed under s 4(1) AWA, provided that the defendant knew, or ought reasonably to have known, that a cat or dog might come into contact with the substance.

The disposal of items which might cause suffering to wild animals is not limited to the disposal of poisonous, noxious, irritating, injurious, etc., substances. The RSPCA website gives a number of examples in which an animal has been harmed by coming into contact with discarded items such as a wheel hub, a plastic can holder, broken glass, a drinks can, a washing machine, a food tin, a fishing net and sharp metal. ${ }^{106}$ It is submitted that, in the examples cited, (i) the reasonable person would appreciate both that it was likely that an animal (including various species of wild animal) would suffer if coming into contact with any of the discarded items and that an animal (again, including species of wild animal) likely would come into contact with the items if

\footnotetext{
106 <http://www.rspca.org.uk/allaboutanimals/helpandadvice/litter> accessed 4 August 2014.
} 
Protecting Wild Animals from Unnecessary Suffering

they were not properly discarded, and (ii) the risk of harm could easily have been avoided by reasonable action, such as disposing of the item at a licensed tip or even, in some cases, simply in a litter bin. Therefore, an offence would be committed under s 4(1) AWA as it currently stands if the animal which suffered unnecessarily was a protected animal, and, if that provision were extended to cover wild animals, an offence would be committed if the animal which suffered unnecessarily was a wild animal, provided that the defendant knew or should have known that a wild animal of the species which suffered would suffer, or would be likely to suffer, as a result of his/her actions.

It could often be hard to prove who discarded a substance or item that caused a wild animal to suffer. However, similar issues abound with, in particular, proof of breaches of s 1 WMPA and the various wildlife protection provisions of the Wildlife and Countryside Act 1981 and the Conservation of Habitats and Species Regulations 2010. If no one witnesses an attack on a wild mammal, the killing or injuring of other protected species, or disposal of a poisonous/injurious substance or item which causes a wild animal to suffer unnecessarily, it will often be extremely difficult to prove any offence. Difficulty of enforcement of a protective law is itself no reason not to offer that protection.

\section{Conclusion}

English law affords wild animals less protection from unnecessary suffering than it affords to animals of commonly domesticated species and those under the control of man, but there has never been proper consideration of whether this different treatment is justified. It has been argued above that extending s 4(1) AWA to protect wild animals from unreasonably caused unnecessary suffering, thereby affording them the same level of protection as non-wild animals, would not cause any problems in practice and can be justified in principle. Various possible reasons for affording greater protection to non-wild animals were considered and rejected as insufficient to justify the different levels of protection. If it is believed that domesticated animals and animals under human 
Protecting Wild Animals from Unnecessary Suffering

control should receive greater legal protection from unnecessary suffering because society owes them a greater moral duty due to their greater vulnerability and people's increased control over them, this should be clearly and openly recognised as the basis of affording wild animals less protection from unnecessary suffering.

A strong analogy can be drawn between (i) protection of animals, wild and non-wild, from unreasonably caused unnecessary suffering under s 4(1) AWA and (ii) the law of negligence. Crucially, both negligence and se 4(1) have the purpose of imposing minimum standards of care on people when their actions might reasonably foreseeably cause injury to another, thereby protecting those who might reasonably foreseeably be injured. Moreover, although s 4(1) AWA is concerned with criminal sanctions, criminal liability for causing unnecessary suffering to non-wild animals has long been based upon objectively unreasonable conduct. As such, extension of s 4(1) AWA to cover wild animals would not introduce a new principle of criminal liability on the basis of "mere" negligence; it would simply extend to wild animals the protection already afforded, for over a century, to non-wild animals.

The practical implications of extending s 4(1) AWA to cover wild animals were also considered. In particular, it was argued that the fact that the provision requires only reasonable conduct and prohibits only unnecessary suffering ensures that it would not extend liability too widely, especially as it has been argued that liability for unnecessary suffering unreasonably caused to wild animals should (i) extend only to commissions, not omissions, and (ii) require proof that it was reasonably foreseeable that an animal of the particular species which suffered would suffer or would be likely to do so. Moreover, although enforcement might be difficult in some cases, this is an inherent problem with protecting wildlife, where offences are often committed out of sight, and offers no justification for not protecting wild animals in the first place. Extending s 4(1) AWA would offer important protection for wild animals and would promote careful, responsible interactions with the natural environment. 